\title{
Acacia nilotica Pods: A Natural Dye Source for Textile Colouration
}

\author{
Dilshad Jamadar* and K.J. Sannapapamma \\ Department of Textile and Apparel Designing, Rural of Home Science, University of \\ Agricultural Sciences, Dharwad-580005, Karnataka, India \\ *Corresponding author
}

\section{Keywords}

Acacia nilotica pods, Colour fastness properties, $\mathrm{K} / \mathrm{S}$ value,

Reflectance value, Single yarn strength and yarn elongation

Article Info

Accepted:

06 December 2017

Available Online:

10 January 2018

\section{A B S T R A C T}

The ban imposed on the usage of synthetic-dyes has led to the reinvention of natural-dyes throughout the world. Today, the faded antiquity is unveiling due to the concern manifested globally for saving the environment from pollution. In this experiment the dried Acacia nilotica pods and degummed mulberry-silk yarn were used. The powdered Acacia nilotica $(5,10,15,20 \mathrm{~g})$ was soaked overnight in different M.L.R (1:20, 1:30, 1:40) to optimize the dye-concentration and it was extracted by aqueous-method. Based on the reflectance and colour-strength, 10g dye-concentration, 1:30 M.L.R, $30 \mathrm{~min}$ extractiontime were optimized for dye-extraction. The pre-treated silk mordanted with different metallic-mordants viz., alum $(5,10,15 \%)$, stannous $(0.5,1.0,1.5 \%)$, copper and ferrous $(1$, $2,3 \%)$ in pre, simultaneous and post mordanting methods and dyed in optimized dyeconcentration in 1:40 M.L.R for 30 min. The dyed silk was assessed for yarn strength, elongation and colour-fastness properties. Irrespective of mordants pre-mordanted dyed silk yarn with alum (15\%), stannous $(0.5 \%)$, copper and ferrous $(3 \%)$ showed increased colour-strength and colour co-ordinates and these mordants were used for mordantcombinations. The silk pre-mordanted with $(15 \%)$ alum showed greater strength and elongation than the other samples. All mordanted samples exhibited good-excellent fastness properties compared to control.

\section{Introduction}

Acacia nilotica is truly multipurpose nitrogen fixing leguminous tree in India commonly called as babul and is a source of gum arabic. It is indigenous in western part of India and northern part of Deccan plateau including Andhra Pradesh, Maharashtra, Rajasthan and Gujarat. It is widely planted and self-grown throughout the hot regions of India viz., Punjab, Haryana, Uttar Pradesh and Karnataka. Acacia nilotica plant is drought resistant and self-grown in dry zone forest of different districts of Karnataka viz., Bellary, Gulbarga, Kolar, Bangalore and Mysore districts. The species can withstand extreme dry environments and can also endure floods. The plant is a good source of fodder especially leaves and dry pods are best supplementary food for cattle's and sheep's instead of green fodder. It is considered as a very important economic plant since early times it was used as a source of tannins, gums, timber, fuel, fodder and medicine. They are important trees 
for lac insects in the Indian subcontinent and gum collected from the trunk and branches was formerly used in paints and medicines. This is frequently used in calico printing and dyeing as a thickening agent (Abhishek, 2015).

Silk being the natural protein fibre possesses lustrous, translucent, good drapability, crisp hand and pleasing appearance. India is the second largest producer and exporter of silk after China. In India, the major silk producing states are Karnataka, Andhra Pradesh, West Bengal, Tamilnadu and Jammu Kashmir. Total mulberry raw silk production in India is 92 per cent and Karnataka is the premier mulberry silk producing state in India contributing yearly 73 per cent of the country's total production. (www.Ibef.Org). It has a greater affinity for natural dyes with better fastness properties and obtain vivid colour shades.

Traditionally Acasia nilotica pods are being used as a dye source for colouring the winnowing bamboo items and door panels in some rural areas of dry zone of Karnataka state. An attempt has been made to explore this source for colouring the textile. Hence, the present study is designed to optimise the dyeing conditions of Acasia nilotica on silk yarn and to study the physical and fastness properties of dyed silk.

\section{Materials and Methods}

The present study was carried out at University of Agricultural Sciences, College of Rural Home Science, Department of Textile and Apparel Designing during the year 20142016.

\section{Raw materials}

Fresh Acacia nilotica pods (Fig. 1) were collected from local forest of Molakalmuru taluk of Chitradurga district, Karnataka. The collected fresh pods were shade dried and crushed into fine powder by traditional pounding technique (Fig. 2). Multivoltine yellow race degummed mulberry silk was procured from Demonstration Cum Training Centre (DCTC), Central Silk Board. Rayapur, Dharwad.

\section{Optimization of dyeing condition}

Optimization of dyeing conditions is essential to get the desired properties of dye source. The powdered Acacia nilotica (5, 10, 15 and $20 \mathrm{~g}$ ) was soaked overnight in different M.L.R (1:20, 1:30 and 1:40) to optimize the dye concentration and it was extracted by aqueous method (Fig. 3). The cooled dye extract was filtered by filter paper and the $\mathrm{pH}$ was recorded $(\mathrm{pH}$ 5-6). The filter extract was subjected to UV spectra photometer to assess the reflectance and colour co-ordinates of dye source. The dyeing variables viz., M.L.R, dye concentration and time of extraction (e.g., 30, 45, $60 \mathrm{~min}$ ) were optimized based on the reflectance and colour co-ordinates value. Based on the reflectance and K/S value, $10 \mathrm{~g}$ dye-concentration, 1:30 M.L.R, $30 \mathrm{~min}$ extraction-time were optimised for dye extraction.

\section{Dyeing of silk yarn}

The degummed mulberry silk yarn pre-treated with myrobolan $(20 \mathrm{~g}$ owf for 1 hour $30 \mathrm{~min}$ ) was dyed with optimised dye concentration (10\% owf) in varied M.L.R (1:20, 1:30, 1:40) and dyeing time(30, 45 and $60 \mathrm{~min})$ intervals. Based on the colour strength (K/S) and colour co-ordinates, 30 min dyeing time and 1:40 M.L.R was optimised for further dyeing (Fig. 4).

Pre-treated silk yarn was mordanted with potash alum (5, 10 and 15\%), copper sulphate and ferrous sulphate (1, 2 and 3\%) and 
stannous chloride $(0.5,1$ and $1.5 \%)$ in pre, simultaneous and post mordanting methods.

Based on the mordanting methods, the mordanted silk yarn dyed with $10 \mathrm{~g}$ dye concentration in optimized dye bath $(1: 40)$ at 30 min dyeing time. When the bath reached boiling temperature the pretreated silk hanks were slowly dipped in dye bath and silk hank were continuously stirred with the help of steel rods to get an even dye absorption. Based on the mordanting methods, mordants were added to the dye bath. In pre mordanting method silk hanks were pre mordanted prior to dyeing, while in simultaneous and post mordanting methods these were added during and after dyeing.

\section{Mordant combinations}

Irrespective of mordants, mordant concentration and mordanting methods, dyed silk yarn were subjected to spectral assessment. Based on the colour strength and colour co-ordinates pre-mordanted dyed silk yarn with alum (15\%), stannous (0.5\%), copper and ferrous (3\%) were used for mordant combinations.

Potash alum + Stannous chloride

Potash alum + Copper sulphate

Potash alum + Ferrous sulphate

Stannous chloride + Copper sulphate

Stannous chloride + Ferrous sulphate

Copper sulphate + Ferrous sulphate

Physical and colour fastness properties of dyed silk yarn

Single mordanted and mordant combination dyed silk yarn was assessed for single yarn strength, elongation and colour fastness properties (Fig. 5).

Shades obtained on silk yarn dyed with Acacia nilotica pods in different mordants were assessed based on visual and coded by panthone colour system (Fig. 6).

\section{Results and Discussion}

\section{Functional group of dye source (GCMS analysis)}

The source was extracted with and analysed by GC-MS as per the test condition at BTRA lab, Mumbai.

Column: RT x 5 MS (30m x $0.25 \mathrm{~mm}$ x 0.25 $\mu \mathrm{m})$

Oven $\quad$ Temperature: $\quad 60^{\circ} \mathrm{C}$ min)@10 $\mathrm{C} / \mathrm{min}, 150^{\circ} \mathrm{C} @ 5^{0} \mathrm{C} / \mathrm{min}$

Injector Temperature: $280^{\circ} \mathrm{C}$

Detector Temperature: $280^{\circ} \mathrm{C}$

The major phenols present in the source are pyrocatechol and pyrogallol. Pyrocatechol is exhibits potential anxiolytic, antinociceptive and antimicrobial properties and is used in pharmaceuticals. Pyrogallol has anticeptic properties and is used in synthetic drugs, medicine and laboratory reagents.

\section{Optimization of dye concentration, extraction time and M.L.R for Acacia nilotica dye}

Table 1 narrates the optimisation of dye concentration, M.L.R and extraction time based on spectral values at 430 wavelength $(\gamma)$. In general, irrespective of dye concentration, M.L.R and dyeing time as the reflectance value increased and the colour strength value decreased and vice versa.

The spectral values of $5 \mathrm{~g}$ dye source compared with standard and test samples explained that the reflectance value decreased (0.472) and K/S value increased (102.308) 
with increasing extraction time in 1:20 M.L.R. However, slightly higher reflectance value (0.500) and lower K/S (99.003) was observed in standard sample compared to test samples. In 1:30 M.L.R. a mixed trend was observed in standard and test samples i.e., higher reflectance and lower K/S values was observed in $60 \mathrm{~min}$ extraction time $(0.487 / 101.67)$ followed by $30 \mathrm{~min}$ $(0.486 / 101.883)$ and $45 \mathrm{~min}(0.468 / 105.840)$. Moreover in 1:40 M.L.R. as the time increased, the reflectance and colour strength of test sample also increased compared to standard. However, highest reflectance value was observed in standard sample indicating (0.483) lower K/S value (101.29) than the test samples.

Irrespective of M.L.R. and extraction time, the $10 \mathrm{~g}$ dye concentration exhibited greater colour strength ranging from 124.743 to 170.08 and lower reflectance values ranging from 0.245 to 0.325 . In the standard sample the reflectance value was high (0.368) with lower K/S value (134.87) compared to test samples. In case of 1:20 liquor bath as the extraction time increased, the $\mathrm{K} / \mathrm{S}$ value also increased with decreased reflectance value indicating that the test samples were darker and had greater colour strength. The liquor bath of 1:30 at different time intervals showed that, in the test samples as the extraction time increased, the reflectance value also increased with decreased K/S value i.e., 0.245/170.3 (30 min), 0.345/139.06 (45 $\mathrm{min}$ ) and 0.352/124.74 (60 $\mathrm{min})$. The results indicated that, as the boiling time increases, the dye concentration became lighter with lower colour strength. This may be due to excess of extraction time and heat application. Hence, the dye source required optimum extraction time and temperature. However, the reflectance of light and colour strength depends on the ratio of dye absorption to scattered by pigmentation, reflective index and the light scattering properties of the dye source.
A similar trend was observed in the standard and test samples extracted in 1:40 M.L.R with different time intervals i.e., $0.359 / 152.85$ (30 min), 0.344/144.35 (45 min) 0.325/138.28 (60 min) of test samples.

Further, the K/S value decreased with increased reflectance value in $15 \mathrm{~g}$ and $20 \mathrm{~g}$ dye concentration compared to $5 \mathrm{~g}$ and $10 \mathrm{~g}$ dye concentrations. In case of $15 \mathrm{~g}$ dye concentration the test samples showed that, the reflectance value decreased with increased M.L.R and extraction time compared to standard sample i.e., 72.75/0.675 (1:20), $74.53 / 0.662(1: 30)$ and 77.87/0.634 (1:40).

Whereas, highest colour strength and least reflectance value was noticed in test samples of 1:30 M.L.R. with different time intervals 81.11 K/S/0.609 R (60 min), $79.13 \mathrm{~K} / \mathrm{S} / 0.624$ $\mathrm{R}$ (30 $\mathrm{min}), 78.88 / 0.626$ (45 $\mathrm{min}$ ) compared to $1: 40$ (80.04/0.617 (45min), 79.52/0.621 (30 $\mathrm{min}), \quad 78.12 / 0.632(60 \mathrm{~min})$ and $1: 20$ (73.07/0.671 (60 min), 72.97/0.674 (45 min), $72.75 / 0.676$ (30 $\mathrm{min})$.

However, the test samples of $20 \mathrm{~g}$ dye concentration depicted that the highest K/S (67.29) and least reflectance value (0.737) was found in 1:30 M.L.R at 60 min extraction time followed by $45 \mathrm{~min}(66.85 / 0.741)$ and $30 \mathrm{~min}$ $(66.48 / 0.748) \quad$ compared to $1: 40$ (67.28/0.720/45 min, 66.40/0.739/30 min. 66.19 and $0.748 / 60 \mathrm{~min}$ ) and 1:20 M.L.R (65.67/0.743/45 min, 64.88/0.750/60 min and $66.79 / 0.759 / 30 \mathrm{~min})$.

On the whole, based on the reflectance and $\mathrm{K} / \mathrm{S}$ values the $10 \mathrm{~g}$ dye concentration in $1: 30$ M.L.R at 30 minutes dyeing time was selected for dye extraction and further used for dyeing of silk yarn.

This concentration exhibited greater colour strength and comparatively lower reflectance value among all the dyeing variables. 
However, ANOVA indicates that, the standard samples exhibited significantly higher reflectance value and lower K/S value than the test samples at 5 per cent level.

Colour strength and colour co-ordinates of dyed silk samples in optimized mordant concentration and mordanting methods

Table 2 represented pulled data of silk yarn dyed with $10 \mathrm{~g}$ dye concentration in varied mordant concentration viz., potash alum (5, $10,15 \%)$, copper sulphate and ferrous sulphate $(1,2,3 \%)$ and stannous chloride $(0.5,1.0$ and $1.5 \%)$ in different M.L.R (1:20, $1: 30$ and 1:40) at varied time $(30,45$ and 60 min) intervals.

Among the mordants the dyed silk yarn mordanted with ferrous sulphate showed higher colour strength (141.54) and darker shades (27.56) in 3 per cent compared to copper sulphate in 3 per cent (30.98 \& 60.47), stannous chloride in 0.5 per cent $(29.72 \&$ 63.12) and potash alum in 15 per cent (16.96 $\&$ 69.98) in pre mordanting method than simultaneous and post mordanting methods.

This may be due to ferrous sulphate a transition metal mordant which forms a large number of complexes with the dye molecules, mostly octahedral ones with coordination number 6. As a result, some co-ordination sites remain unoccupied, when these sites interact with the fiber, the functional groups of silk fibre such as amino and carboxylic groups can occupy these unoccupied sites. Thus, ferrous sulphate salts can form a ternary complex on one site with the fiber and in the other site with the dye. Thus resulting into higher dye uptake with darker shade and greater colour strength of silk yarn mordanted with ferrous sulphate (Uddin, 2014).

The various shades obtained from dyed silk mordanted with alum and copper were light brown to dark olive green, whereas obtained from stannous were light brown to dark cream and with ferrous dark coffee brown to light ash were obtained.

Effect of mordants, mordanting methods and mordant concentration on single yarn strength (kgf) and elongation (\%)

It is clear from the Table 3 that the yarn strength of post mordanted silk yarn with 1 percent ferrous sulphate $(0.21 \mathrm{kgf})$ showed significantly greater strength followed by potash alum and copper sulphate in simultaneous and stannous chloride in pre mordanting method $(0.20 \mathrm{kgf})$ compared to control $(0.15 \mathrm{kgf})$ samples.

Results indicated that, mordanted silk samples exhibited greater strength than the control sample. This may be due to deposition and penetration of mordants on the surface of the fibre polymers and fibre core which in turn added weight and strength to the dyed silk yarn. These results are on par with the results of Saikam et al., (2015).

The yarn elongation of silk yarn mordanted with 1 percent copper sulphate in simultaneous mordanting method $(12.43 \%)$ showed significantly greater elongation followed by ferrous sulphate (Post / $11.65 \%$ ), stannous chloride (Pre / $11.45 \%$ ) and potash alum (Simultaneous / $10.61 \%$ ) compared to control $(9.55 \%)$ samples. The mordanted dyed silk yarn showed greater elongation percentage than the control sample. This may be because of a strong co-ordination between fibre-mordant-dye due to heat application and increased strength and crimp percentage than the control sample (Durah, 2013).

The control sample i.e., myrobolan pretreated Acacia nilotica dyed silk yarn showed lower yarn strength and elongation than the silk pretreated with different mordant combinations. 
Int.J.Curr.Microbiol.App.Sci (2018) 7(1): 602-612

Table.1 Optimisation dye concentrations, M.L.R and boiling time of Acacia nilotica dye based on spectral values at 430 wavelength $(\lambda)$

\begin{tabular}{|c|c|c|c|c|c|c|c|c|c|c|c|c|c|}
\hline \multirow{2}{*}{$\begin{array}{c}\text { Dye } \\
\text { concentratio } \\
\text { n (gm) } \\
\end{array}$} & \multirow{2}{*}{$\begin{array}{c}\text { Spectral } \\
\text { Values }\end{array}$} & \multirow[t]{2}{*}{ Control } & \multicolumn{3}{|c|}{$1: 20$} & \multirow[t]{2}{*}{ Control } & \multicolumn{3}{|c|}{$1: 30$} & \multirow[t]{2}{*}{ Control } & \multicolumn{3}{|c|}{$1: 40$} \\
\hline & & & $30 \mathrm{~min}$ & 45 min & $60 \mathrm{~min}$ & & $30 \mathrm{~min}$ & $45 \mathrm{~min}$ & 60 min & & 30 min & 45 min & $60 \mathrm{~min}$ \\
\hline \multirow[t]{2}{*}{5} & RFL & 0.500 & 0.495 & 0.484 & 0.472 & 0.497 & 0.487 & 0.468 & 0.486 & 0.483 & 0.481 & 0.399 & 0.310 \\
\hline & $\mathrm{K} / \mathrm{S}$ & 99.003 & 100.013 & 101.218 & 102.308 & 99.606 & 101.883 & 105.840 & 101.672 & 101.297 & 102.522 & 102.384 & 103.482 \\
\hline \multirow[t]{2}{*}{10} & RFL & 0.368 & 0.361 & 0.358 & 0.348 & 0.357 & 0.245 & 0.352 & 0.345 & 0.356 & 0.344 & 0.325 & 0.359 \\
\hline & $\mathrm{K} / \mathrm{S}$ & 134.871 & 137.506 & 138.667 & 142.680 & 136.743 & 170.080 & 139.058 & 124.743 & 139.451 & 144.351 & 152.848 & 138.278 \\
\hline \multirow[t]{2}{*}{15} & RFL & 0.678 & 0.676 & 0.674 & 0.671 & 0.662 & 0.624 & 0.626 & 0.609 & 0.634 & 0.621 & 0.617 & 0.632 \\
\hline & $\mathrm{K} / \mathrm{S}$ & 72.750 & 72.750 & 72.968 & 73.077 & 74.532 & 79.131 & 78.875 & 81.105 & 77.868 & 79.518 & 80.040 & 78.117 \\
\hline \multirow[t]{2}{*}{20} & RFL & 0.760 & 0.759 & 0.743 & 0.750 & 0.753 & 0.748 & 0.741 & 0.737 & 0.762 & 0.739 & 0.720 & 0.748 \\
\hline & $\mathrm{K} / \mathrm{S}$ & 64.621 & 64.793 & 65.670 & 64.880 & 66.298 & 66.480 & 66.846 & 67.205 & 65.153 & 66.405 & 67.289 & 66.189 \\
\hline
\end{tabular}

ANOVA TABLE

\begin{tabular}{|c|c|c|c|c|c|c|c|c|c|c|}
\hline \multirow{2}{*}{$\begin{array}{l}\text { Dye concentration } \\
\text { (gm) }\end{array}$} & \multirow{2}{*}{$\begin{array}{l}\text { Spectral } \\
\text { Values }\end{array}$} & \multicolumn{3}{|c|}{$1: 20$} & \multicolumn{3}{|c|}{ 1:30 } & \multicolumn{3}{|c|}{$1: 40$} \\
\hline & & S.Emt & $\mathrm{CD}(5 \%)$ & CV\% & S.Emt & $\mathrm{CD}(5 \%)$ & CV\% & S.Emt & $\begin{array}{c}\mathrm{CD} \\
(5 \%)\end{array}$ & CV\% \\
\hline \multirow[t]{2}{*}{5} & RFL & 0.019 & $0.027 *$ & 8.935 & 0.013 & $0.018 *$ & 5.796 & 0.012 & $0.017 *$ & 6.581 \\
\hline & $\mathrm{K} / \mathrm{S}$ & 0.472 & $0.651 *$ & 1.043 & 0.003 & $0.004 *$ & 0.006 & 0.001 & $0.001 *$ & 0.001 \\
\hline \multirow[t]{2}{*}{10} & RFL & 0.001 & $0.002 *$ & 0.788 & 0.001 & $0.001 *$ & 0.685 & 0.001 & $0.001 *$ & 0.511 \\
\hline & $\mathrm{K} / \mathrm{S}$ & 0.004 & $0.005 *$ & 0.006 & 0.004 & $0.005 *$ & 0.006 & 0.001 & $0.001 *$ & 0.001 \\
\hline \multirow[t]{2}{*}{15} & RFL & 0.001 & $0.001 *$ & 0.253 & 0.001 & $0.001 *$ & 0.290 & 0.001 & $0.001 *$ & 0.278 \\
\hline & $\mathrm{K} / \mathrm{S}$ & 0.005 & $0.007 *$ & 0.016 & 0.001 & $0.001 *$ & 0.002 & 0.004 & $0.005 *$ & 0.012 \\
\hline \multirow[t]{2}{*}{20} & RFL & 0.005 & $0.006 *$ & 1.449 & 0.001 & $0.001 *$ & 0.233 & 0.004 & $0.005^{*}$ & 1.158 \\
\hline & $\mathrm{K} / \mathrm{S}$ & 0.006 & $0.008 *$ & 0.019 & 0.003 & $0.005 *$ & 0.013 & 0.001 & $0.001 *$ & 0.003 \\
\hline
\end{tabular}

*Significant @ 5\% level 
Table. 2 Colour strength and colour co-ordinates of dyed silk samples in optimized mordant concentration and mordanting methods

\begin{tabular}{|c|c|c|c|c|}
\hline \multirow{3}{*}{$\begin{array}{l}\text { Colour } \\
\text { co- } \\
\text { ordinates }\end{array}$} & \multicolumn{4}{|c|}{ Pre mordanting method } \\
\hline & Potash alum & Stannous chloride & Copper sulphate & Ferrous sulphate \\
\hline & $15 \%$ & $0.5 \%$ & $3 \%$ & $3 \%$ \\
\hline $\mathbf{K} / \mathbf{S}$ & $\begin{array}{c}16.96 \\
(38.17)\end{array}$ & $\begin{array}{c}29.72 \\
(32.15)\end{array}$ & $\begin{array}{c}30.98 \\
(25.72)\end{array}$ & $\begin{array}{c}141.54 \\
(13.18)\end{array}$ \\
\hline $\mathbf{L}^{*}$ & $\begin{array}{c}69.98 \\
(29.07)\end{array}$ & $\begin{array}{c}63.12 \\
(24.57)\end{array}$ & $\begin{array}{c}60.47 \\
(-21.52)\end{array}$ & $\begin{array}{c}27.56 \\
(-11.31)\end{array}$ \\
\hline$a^{*}$ & $\begin{array}{c}2.69 \\
(-5.05)\end{array}$ & $\begin{array}{c}5.75 \\
(-1.58)\end{array}$ & $\begin{array}{c}5.78 \\
(-1.84)\end{array}$ & $\begin{array}{c}5.39 \\
(-1.85)\end{array}$ \\
\hline$\overline{b^{*}}$ & $\begin{array}{c}27.97 \\
(17.40)\end{array}$ & $\begin{array}{c}29.72 \\
(-20.64)\end{array}$ & $\begin{array}{c}24.34 \\
(-13.95)\end{array}$ & $\begin{array}{c}3.94 \\
(-6.38)\end{array}$ \\
\hline \multirow[t]{2}{*}{$\begin{array}{c}\text { Colours } \\
\text { obtained }\end{array}$} & & & & \\
\hline & $\begin{array}{l}\text { Dark Olive green } \\
\text { (Panthone } 4625 \mathrm{M})\end{array}$ & $\begin{array}{c}\text { Dark brown } \\
\text { (Panthone } 4645 \mathrm{M})\end{array}$ & $\begin{array}{l}\text { Dark olive green } \\
\text { (Panthone } 4625 \mathrm{M})\end{array}$ & $\begin{array}{c}\text { Dark coffee brown } \\
\text { (Panthone } 6 \mathrm{M})\end{array}$ \\
\hline
\end{tabular}

Figures in parenthesis indicate $\mathrm{K} / \mathrm{S}(\Delta \mathrm{E}), \mathrm{L} *(\Delta \mathrm{L}), \mathrm{a}^{*}(\Delta \mathrm{a}), \mathrm{b}^{*}(\Delta \mathrm{b})$

K/S- Colour strength

L-The lightness/darkness co-ordinate

$\mathrm{a}^{*}$ - The red/green co-ordinate with $+\mathrm{a}^{*}$ indicating red $-\mathrm{a}^{*}$ indicating green

$\mathrm{b} *$ - The yellow/blue co-ordinate with $+\mathrm{b}^{*}$ indicating yellow and $-\mathrm{b}^{*}$ indicating blue

Table.3 Effect of mordants, mordanting methods and mordant concentration on single yarn strength (kgf) and elongation (\%)

\begin{tabular}{|c|c|c|c|c|}
\hline Mordants & $\begin{array}{c}\text { Mordanting } \\
\text { method }\end{array}$ & $\begin{array}{c}\text { Mordant } \\
\text { concentration }\end{array}$ & $\begin{array}{c}\text { Strength } \\
(\mathbf{k g f})\end{array}$ & $\begin{array}{c}\text { Elongation } \\
(\%)\end{array}$ \\
\hline Control & - & - & 0.15 & 9.55 \\
\hline Potash alum (PA) & Simultaneous & $10 \%$ & 0.20 & 10.61 \\
\hline $\begin{array}{c}\text { Stannous chloride } \\
\text { (SC) }\end{array}$ & Pre & $1.5 \%$ & 0.20 & 11.45 \\
\hline Copper sulphate (CS) & Simultaneous & $1 \%$ & 0.20 & 12.43 \\
\hline Ferrous sulphate (FS) & Post & $1 \%$ & 0.21 & 11.65 \\
\hline Mordant combinations & & & & \\
\hline Control & - & - & 0.15 & 9.55 \\
\hline SC+FS & Pre & $3 \%+0.5 \%$ & 0.24 & 12.74 \\
\hline CS+SC & & $15 \%+0.5 \%$ & 0.32 & 13.48 \\
\hline PA+SC & & $15 \%+3 \%$ & 0.25 & 11.50 \\
\hline PA+CS & & $15 \%+3 \%$ & 0.27 & 12.95 \\
\hline PA+FS & & $3 \%+3 \%$ & 0.21 & 9.80 \\
\hline CS+FS & & -1.40 & & \\
\hline
\end{tabular}

Dye concentration $-10 \mathrm{~g}$ Dyeing time $30 \mathrm{~min}$ M.L.R ratio $-1: 40$ 
Table.4 Colour fastness properties of mordanted silk yarn dyed with Acacia nilotica pods

\begin{tabular}{|c|c|c|c|c|c|c|c|c|c|c|c|c|c|c|c|c|}
\hline \multirow{4}{*}{ 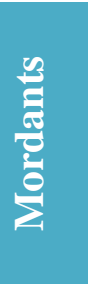 } & \multirow{4}{*}{ 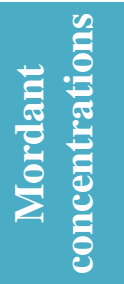 } & \multirow{4}{*}{ 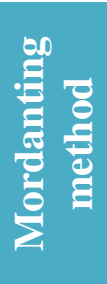 } & \multicolumn{4}{|c|}{ Rubbing } & \multicolumn{6}{|c|}{ Perspiration } & \multirow{4}{*}{$\begin{array}{l}\text { Sunlight } \\
\text { CC }\end{array}$} & \multicolumn{3}{|c|}{ Washing } \\
\hline & & & \multicolumn{2}{|c|}{ Dry } & \multicolumn{2}{|c|}{ Wet } & \multicolumn{3}{|c|}{ Acid } & \multicolumn{3}{|c|}{ Alkali } & & & & \\
\hline & & & \multirow[t]{2}{*}{$\mathrm{CC}$} & \multirow[t]{2}{*}{ CS } & \multirow[t]{2}{*}{$\mathrm{CC}$} & \multirow[t]{2}{*}{ CS } & \multirow[t]{2}{*}{$\mathrm{CC}$} & \multicolumn{2}{|c|}{ CS } & \multirow[t]{2}{*}{$\mathrm{CC}$} & \multicolumn{2}{|c|}{$\mathbf{C C}$} & & \multirow[t]{2}{*}{$\mathrm{CC}$} & \multicolumn{2}{|c|}{ CS } \\
\hline & & & & & & & & $\mathbf{S}$ & $\mathbf{C}$ & & $\mathbf{S}$ & $\mathbf{C}$ & & & $\mathbf{S}$ & C \\
\hline $\begin{array}{l}\text { Con } \\
\text { trol }\end{array}$ & - & - & $4 / 5$ & 4 & 4 & $3 / 4$ & 4 & $4 / 5$ & $3 / 4$ & 4 & 5 & 5 & 4 & 4 & 5 & 5 \\
\hline PA & $15 \%$ & Pre & 5 & $4 / 5$ & 4 & $4 / 5$ & $4 / 5$ & 5 & 5 & $4 / 5$ & 5 & 5 & $4 / 5$ & $4 / 5$ & 5 & 5 \\
\hline CS & $3 \%$ & & 5 & 5 & $4 / 5$ & $4 / 5$ & $4 / 5$ & $4 / 5$ & $4 / 5$ & $4 / 5$ & 5 & 5 & $4 / 5$ & $4 / 5$ & 5 & 5 \\
\hline SC & $0.5 \%$ & & 5 & $4 / 5$ & $4 / 5$ & $3 / 4$ & $4 / 5$ & $4 / 5$ & $4 / 5$ & $4 / 5$ & 5 & 5 & $4 / 5$ & $4 / 5$ & 5 & 5 \\
\hline FS & $3 \%$ & & 5 & $4 / 5$ & 4 & $4 / 5$ & 5 & 5 & 5 & $4 / 5$ & 5 & 5 & $4 / 5$ & $4 / 5$ & 5 & 5 \\
\hline
\end{tabular}

Note: CC- Colour change CS- Colour staining

1-Very poor, 2-Poor, 3-Fair, 4-Good, 5-Excellent

PA-Potash alum CS-Copper sulphate SC-Stannous chloride FS-Ferrous sulphate

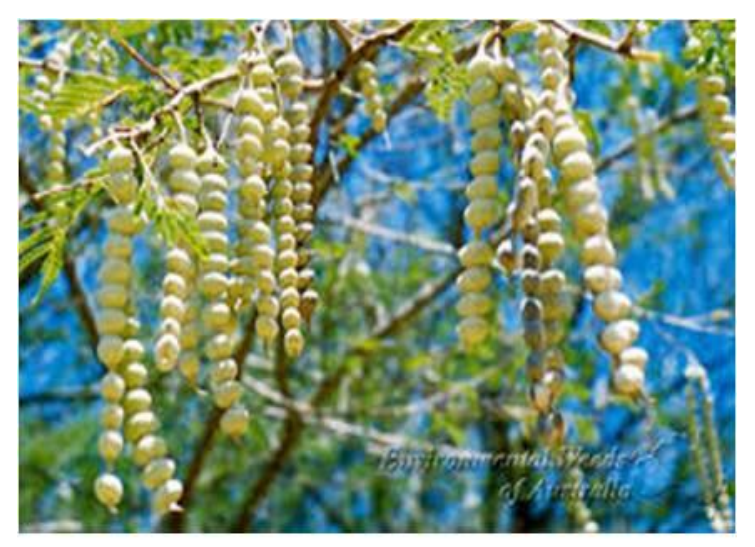

Fig 1. Acacia nilotica pods

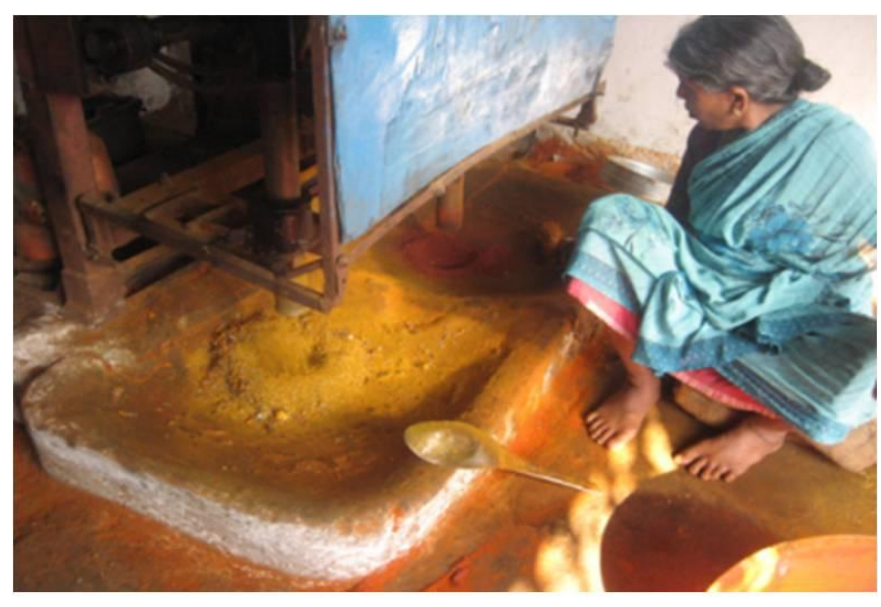

Fig 2. Ponding technique Of Acacia nilotica pods 


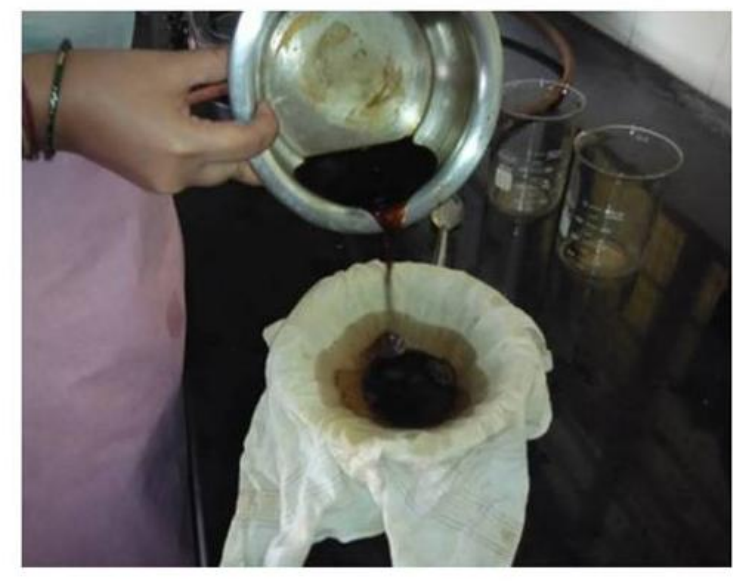

Fig 3. Extraction of Acacia nilotica dye

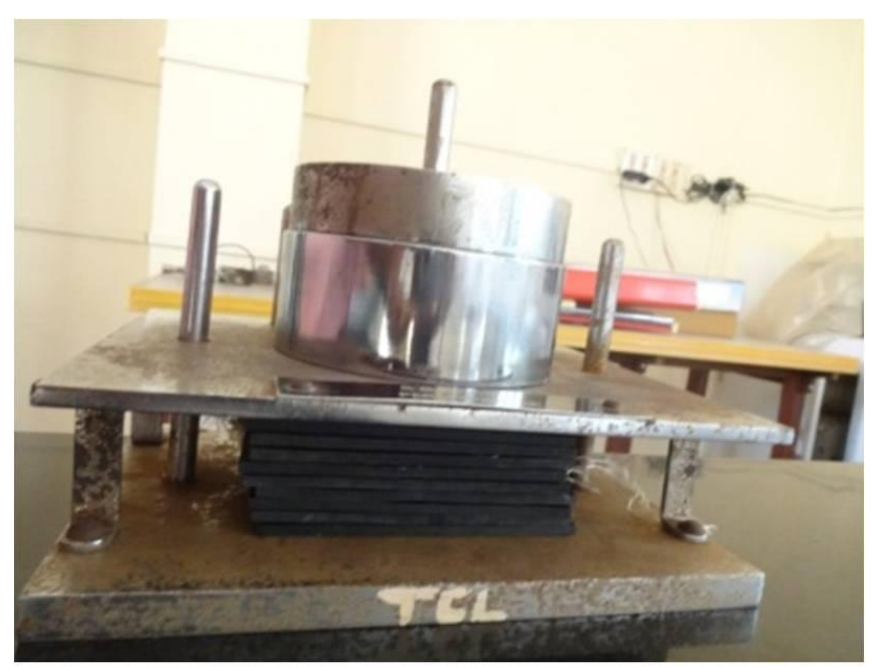

Fig 5. Colour fastness to Perspiration

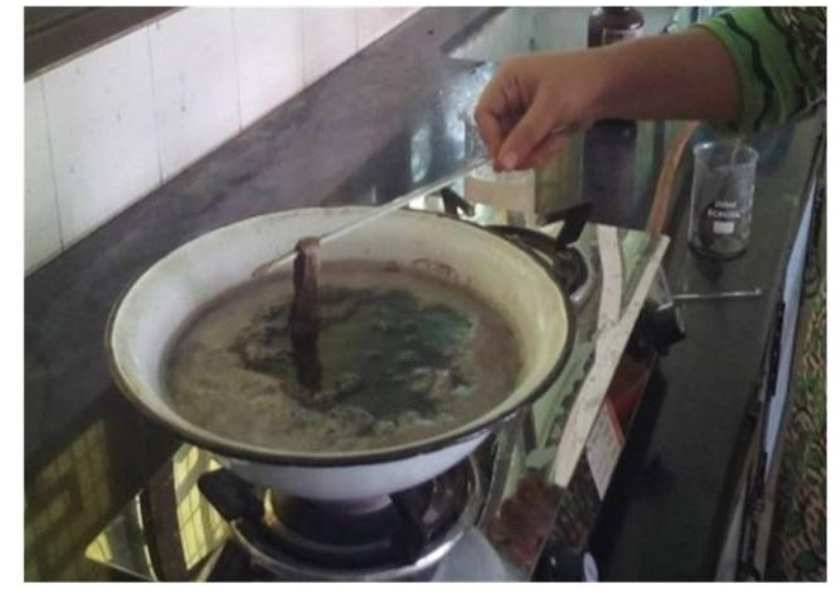

Fig 4. Dyeing silk yarn with Acacia nilotica dye

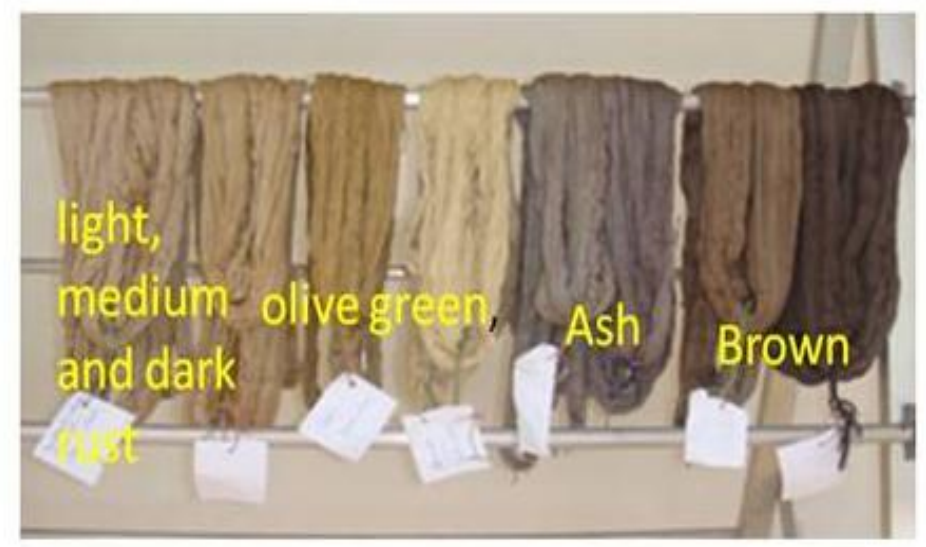

Fig 6. Acacia nilotica dyed samples. 


\section{PYROCATECHOL}

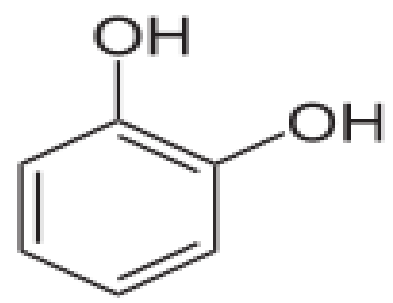

Among the mordant combinations, yarn strength was found to be more in potash alum + stannous chloride $(0.32)$ followed by stannous chloride + ferrous sulphate $(0.28)$, potash alum + ferrous sulphate $(0.270$, potash alum + copper sulphate $(0.25)$, copper sulphate + stannous chloride (0.24) and copper sulphate + ferrous sulphate (0.21) compared to control sample (0.15).

However, the elongation results showed that the mean elongation was found to be higher in potash alum + stannous chloride (13.48) than the other mordant combinations i.e., copper sulphate + stannous chloride (13.19), potash alum + ferrous sulphate (12.95), stannous chloride + ferrous sulphate (12.74), potash alum + copper sulphate (11.50) and copper sulphate + ferrous sulphate (9.80) compared to control sample (9.55). This may be due to, potash alum known as double salt and it has one kind of anion $\left(\mathrm{So}_{4}{ }^{2-}\right.$ ion) balanced by two cations $\mathrm{K}^{+}$ and $\mathrm{Al}^{3+}$ anchored with silk $-\mathrm{NH}^{2}$ bonds which may strengthen the silk yarn. Further, silk yarn pre mordanted with higher amount of potash alum (15\%) and very less amount of stannous chloride showed good additive property which may contribute for improvement of strength and elongation of dyed silk yarn (Samanta and Konar, 2010).

\section{Colour fastness properties of mordanted silk yarn dyed with Acacia nilotica pods}

Colourfastness to dry crocking (4/5 to 5) was found to be good to excellent compared to wet crocking fair to good (3/4 to 4/5) in all the mordant concentration and mordanting methods of dyed silk samples. This may be due to
PYROGALLO

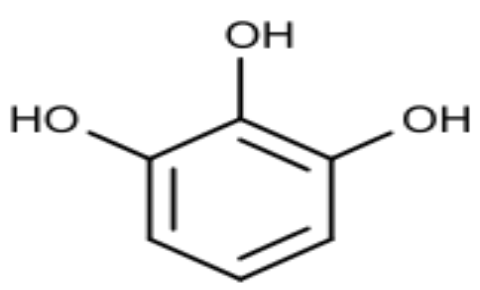

breakage of dye metal complexes into simple particles during wet crocking and release of superficially deposited dye molecules from dry substance to wet, thus resulting into slight stain on the material (Table 4).

However, the mordanted silk samples showed good to excellent colour fastness to perspiration (4-5) than the control sample which may be due to the combined effect of mordants-fibre-dye.

Irrespective of mordanting methods and mordant concentrations, the mordanted samples showed good to excellent (4/5) colourfastness to sunlight compared to control (3). It may be due to the stable arrangement of electrons which is resistant to photo degradation by the UV rays stated by Gohl and Vilensky (1987).

It was interesting to observe that, all the silk samples dyed in Acacia nilotica possessed good fastness to washing. This may be due toeffect of dye fixing agents (mordants), dye $\mathrm{OH}^{+}$group and silk $-\mathrm{NH}^{2}$ group may combine to form insoluble bigger size complex either inside the fibre or on the surface of the dyed fibres to improve their wash fastness properties.

The lower reflectance and higher colour strength value was found in lower dye concentration i.e., $5 \mathrm{~g}$ and $10 \mathrm{~g}$ dye concentrations with varied M.L.R (1:20, 1:30 and 1:40) and time intervals (30,45 and $60 \mathrm{~min}$ ) than the 15 and $20 \mathrm{~g}$ dye concentration.

Among the mordants, silk yarn mordanted with ferrous sulphate in 3 per cent showed higher colour strength and darker shades followed by copper sulphate, stannous chloride and potash 
alum in pre mordanting method than simultaneous and post mordanting method.

Ferrous sulphate (1\%) pre mordanted dyed silk yarn showed greater strength $(0.21 \mathrm{kgf})$ than the control and other test samples.

Copper sulphate mordanted dyed silk yarn showed maximum elongation (12.43\%) compared to control and other mordanted samples.

Good to excellent colour fastness was observed for dry crocking than wet crocking of all the samples.

The dyed silk exhibited good colour fastness to acidic perspiration than alkaline

Control and mordanted silk samples exhibited good to excellent light fastness.

In view of the superior colour values and acceptable fastness properties of Acacia nilotica dyed silk yarn can be effectively used for producing value added environment friendly dyed textile products. It can be concluded that, Acacia nilotica pods are good source for dyeing silk and other fibre with different mordants and mordant concentrations. Using mordant combinations yield vivid colours than the single mordants. A fodder source is now being used effectively for colouration of textiles in ecofriendly way. However, the pod has rich source of pyrogallol and pyrocatechol which impart not only colour to the textiles but also has good antioxidant and UV protection properties. Hence, local dyers can effectively use this source for colouration of textiles. Further, propagation / planting of Acacia nilotica trees in dry forest zone in local districts of Karnataka state can provide source of enterprise and sustainable approach to the rural artisans and local dyers.

\section{Acknowledgement}

Author's sincerely thank Mr. Itagi, Deputy Director, DCTC, Central Silk Board, Rayapura Dharwad for providing silk and lab facility for conducting colour fastness trials.

\section{References}

Abhishek R, Haokip, Vand Chandrawanshi S, Acacia nilotica: a multipurpose tree and source of Indian gum Arabic, South Indian Journal of Biological Sciences, 1(2) 2015 66-69.

DuarahPand Kaur S, A study on the effect of Telanthera ficoidea dye on mulberry silk, Asian Journal of Home Science, 8(1): 2013 269-276.

Gohl EPG and Vilensky LD, Textile Science Edn-1, CBS Publishers and Distributors, New Delhi 1987, Pp. 120-130.

Saikam A, Schefer RT and Vaidya, Fundamentals to textiles, CBS publishers and PVT distributers India, 2015, 230235.

Samanta AK and Konar A, Dyeing of Textiles with natural dyes, J Inst Engg. Text Engg, 91(7): 2010 30-56.

Uddin MG, Effects of Different Mordants on Silk Fabric Dyed with Onion Outer Skin Extracts. Journal of Textiles, 97(2): 2014 $1-8$.

www.ibef.Org

\section{How to cite this article:}

Dilshad Jamadar and Sannapapamma, K.J. 2018. Acacia nilotica Pods: A Natural Dye Source for Textile Colouration. Int.J.Curr.Microbiol.App.Sci. 7(01): 602-612. doi: https://doi.org/10.20546/ijcmas.2018.701.073 